\title{
The Influence of Slight Protuberances in a Micro-Tube Reactor on Methane/Moist Air Catalytic Combustion
}

\author{
Ruirui Wang ${ }^{1,2}$, Jingyu Ran ${ }^{1,2, *}$, Xuesen Du ${ }^{1,2}$, Juntian Niu ${ }^{2}$ and Wenjie $\mathrm{Qi}^{2}$ \\ 1 Key Laboratory of Low-Grade Energy Utilization Technologies and Systems of Ministry of Education, \\ Chongqing University, Chongqing 400044, China; wangrui2233@126.com (R.W.); \\ xuesendu@cqu.edu.cn (X.D.) \\ 2 College of Power Engineering, Chongqing University, Chongqing 400044, China; 13648334078@189.cn (J.N.); \\ qi_diracjie@163.com (W.Q.) \\ * Correspondence: ranjy@cqu.edu.cn; Tel./Fax: +86-23-6511-1832
}

Academic Editors: Antonio Ficarella and Maria Grazia De Giorgi

Received: 23 March 2016; Accepted: 15 May 2016; Published: 30 May 2016

\begin{abstract}
The combustion characteristics of methane/moist air in micro-tube reactors with different numbers and shapes of inner wall protuberances are investigated in this paper. The micro-reactor with one rectangular protuberance (six different sizes) was studied firstly, and it is shown that reactions near the protuberance are mainly controlled by diffusion, which has little effect on the outlet temperature and methane conversion rate. The formation of cavities and recirculation zones in the vicinity of protuberances leads to a significant increase of the Arrhenius reaction rate of $\mathrm{CH}_{4}$ and gas velocity. Next, among the six different simulated conditions (0-5 rectangular protuberances), the micro-tube reactor with five rectangular protuberances shows the highest methane conversion rate. Finally, the effect of protuberance shape on methane/moist air catalytic combustion is confirmed, and it is found that the protuberance shape has a greater influence on methane conversion rate than the number of protuberances. The methane conversion rate in the micro-tube decreases progressively in the following order: five triangular slight protuberances $>$ five rectangular protuberances $>$ five trapezoidal protuberances $>$ smooth tube. In all tests of methane/moist air combustion conditions, the micro-tube with five triangular protuberances has the peak efficiency and is therefore recommended for high efficiency reactors.
\end{abstract}

Keywords: micro-tube reactor; slight protuberances; methane/moist air; catalytic combustion

\section{Introduction}

With micro-combustion gradually becoming a significant technology for energy production, the miniaturization of devices such as micro-thrusters, micro-engines, micro-robots, and micro-combustors, etc. in Micro-electromechanical Systems (MEMS) [1-4] has become an important subject. Compared with traditional combustors, the heating area of a MEMS reactor is about $1 \mathrm{~mm}^{2}$, or no more than $1 \%$ of the size of traditional combustors $[5,6]$. In the micro-reactor, the surface-to-volume ratio (S/V) increases and the residence time of gas mixtures in the micro combustion chamber is reduced, which results in high thermal losses, high free radical losses, and even flameouts, etc. Most researchers believe that catalytic combustion [7,8] is an effective way in reducing the heat losses and enhancing the combustion stability under the fuel-lean conditions [9]. Studies [10-12] have shown that catalysts deposited on the combustor walls can sustain chemical reactions at lower temperatures, reduce thermal/free radical quenching and pollutant emissions.

In the field of micro-scale catalytic combustion for energy production [13-15], most researchers focus on the use of natural gas, methane, as the main component [16-18], which is regarded as a clean, renewable and universal fuel [19-21]. Moreover, natural gas is an attractive alternative fossil 
fuel which could reduce pollutant emissions and lower the energy dependence on fossil oil [14,15,22]. However, methane is considered the most stable hydrocarbon and is difficult oxidize, and its catalytic ignition requires relatively high temperatures even on expensive Pt- or Pd-based catalysts [23-27]. Therefore, preheating the inlet mixture gases [28], adding hydrogen to the methane fuel $[29,30]$ and improved catalyst layout designs $[31,32]$ have been proposed in succession to improve the combustion efficiency in micro-reactors.

Previous studies indicated that proper micro-combustor configurations [7,31,33-36] and well-designed catalyst beds [37-39] can reduce heat/radical losses and improve the combustion efficiency. Li et al. [9] developed a small-scale wire-mesh catalytic combustor for hydrogen-syngas combustion, and their experimental results indicated that the double-layer wire-mesh catalytic combustor could yield a higher CO conversion ratio $(>90 \%)$ than that of a single-layer wire-mesh catalyst $(<40 \%)$. A catalyst segmentation configuration with cavities has also been proposed to promote methane conversion in a micro-reactor [9]. Baigmohammadi et al. [7] numerically investigated a micro-reactor equipped with a catalytic bluff body, and showed that compared to the catalytic wall, the manufacturing process is more convenient when using the catalytic bluff body. Ran et al. [37] investigated the characteristics of methane catalytic combustion in micro-channels with a concave or convex wall cavity, they found that temperature reaches a peak in a convex cavity, because heat transfer in the convex micro-channel is enhanced and the temperature distribution is more uniform; It is suggested thus that combustors with a convex cavity are more suitable for methane catalytic combustion at low velocity. Wan et al. [40] studied the impact of channel gap distance on the "flame splitting limit", and a non-monotonic dependence of the "flame splitting limit" factor on the channel gap was found. Zhang et al. [41] have numerically investigated the transient characteristics of the auto-thermal reforming of methane in a cube micro-combustor with multiple cylinders; the results revealed that the micro-combustor has the properties of high heat resistance, less thermal expansion and low cost. Niu et al. [42] numerically investigated the effects of five trapezoidal bluff bodies on the blowout limit of methane/air combustion in a micro-channel, and the results showed that the shape changes of bluff bodies have a slight effect on blowout limit for the same blockage ratio, the combustion recirculation zone is favorable to improve the micro-channel temperature and extend the mixture gas residence time, while the shape changes of the five trapezoidal bluff bodies have little effect on the expansion of the combustion recirculation zone.

As for the influence of heat recirculation on flame stability and speed in micro-combustors, Veeraragavan et al. [43] have developed an analytical model for flame stabilization in meso-scale channels and categorically shown the influence of heat recirculation on the flame stability and speed. They found that combustor design parameters (such as the wall thickness ratio, thermal conductivity ratio and heat loss to the environment) influence the flame speed through their influence on the total heat recirculation. Recently, the influence of orthotropic wall materials on the flame speed was investigated by Veeraragavan [44], whereby the effects of orthotropic wall thermal conductivities, heat loss, and wall thickness on the flame speed were explored, and the results indicated that total heat recirculation is the primary parameter that controls the flame speed. The first ever experimental demonstration of the use of orthotropic walls in microcombustors has been realized by Kang and Veeraragavan [45], who showed that the flammability limits can be enhanced due to the heat conduction through the plates is enhanced at large mixture flow rates. The first-ever verification procedure using manufactured solutions for compressible conjugate heat transfer solvers has been executed successfully by Veeraragavan and co-workers [46], and the newly developed solid heat transfer solver is found to have no apparent coding errors and such solvers are required for micro-combustor simulations.

However, most literatures focus on the reactor size, different catalyst layouts, catalyst segmentation with cavities, or the shape and location of bluff bodies, and research on the inner wall structures is sufficiently advanced, but it is still necessary to obtain comprehensive data on the catalytic combustion properties, including the effect of wall features. Therefore, the present paper reports an in-depth study from the point of view of wall structures to improve the methane conversion. 
In this work, the effect of single different sizes of rectangular protuberances in a circular tube reactor was investigated separately. Then, the number of the rectangular protuberance $(0.2 \mathrm{~mm} \times 0.1 \mathrm{~mm})$ in the circular tube reactor was increased from 0 to 5 , and subsequently the distance from the entrance of the five rectangular protuberances was set at $0.5,1.7,3.4,5.6$ and $8.3 \mathrm{~mm}$. Finally, the combustion characteristics of five rectangular, triangular and trapezoidal protuberances and smooth tube walls were simulated, respectively.

\section{Numerical Methods}

\subsection{Physical Model}

In order to investigate the influence of different inner wall structures on methane/moist air catalytic combustion, several slight protuberances with different sizes, spacing and shapes were added to the inner walls of micro-tubes. The physical model is a micro-tube reactor. The material of the micro-tubes is aluminum and all of the inner walls are coated with platinum $(\mathrm{Pt})$ catalyst. The length, the inner diameter and the wall thickness of the reactor are 10,1 and $0.1 \mathrm{~mm}$, respectively. Figure $1 \mathrm{~A}$ shows the dimensions of the single rectangular protuberances studied. The shapes and sizes of the different protuberances on the inside walls are shown in Figure 1B,C. Figure 1C presents the structure of a smooth tube and micro-tubes with five slight protuberances of different shapes. The distances of the multiple protuberances of different shapes from the reactor entrance are 0.5, 1.7, 3.4, 5.6 and $8.3 \mathrm{~mm}$, respectively. Three calculation cases and the configurations of the relative reactors are listed in Table 1.

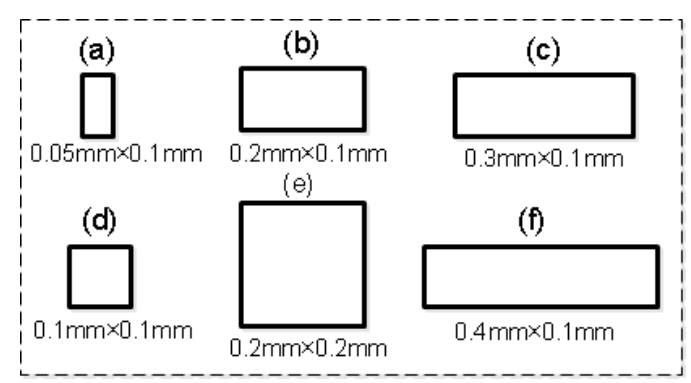

(A)

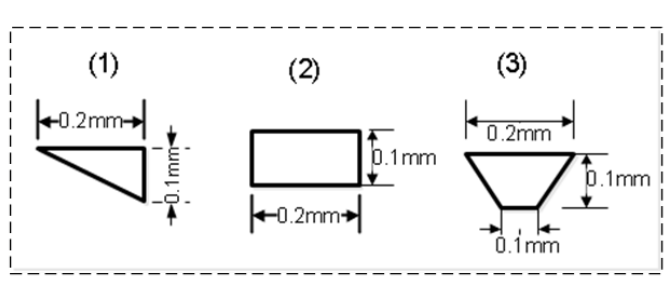

(B)
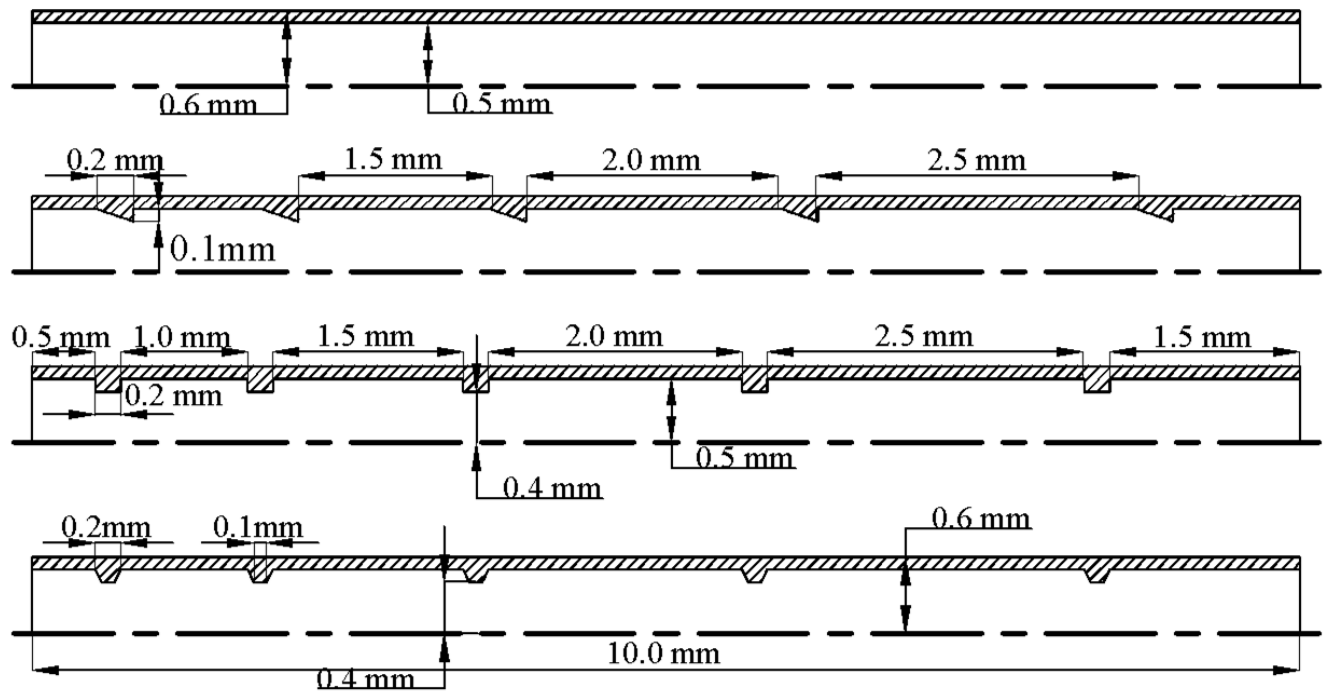

(C)

Figure 1. Schematic diagram of physical model: (A) the sizes of single rectangular protuberances; (B) slight protuberance structures of different shape; (C) the case of five protuberances for three different shapes. 
Table 1. The three calculation cases of the work.

\begin{tabular}{|c|c|c|c|c|}
\hline $\begin{array}{l}\text { Working } \\
\text { Conditions }\end{array}$ & $\begin{array}{l}\text { Protuberance } \\
\text { Number }\end{array}$ & $\begin{array}{l}\text { Protuberance } \\
\text { Shape }\end{array}$ & Protuberance Size & $\begin{array}{l}\text { Distance from Entrance } \\
\qquad(\mathrm{mm})\end{array}$ \\
\hline Case 1 & 1 & Rectangular & $\begin{array}{l}\text { Six different sizes } \\
\text { see Figure } 1 \mathrm{~A}\end{array}$ & 0.5 \\
\hline Case 2 & $1,2,3,4,5$ & Rectangular & $\begin{array}{l}\text { One fixed size: } \\
0.2 \mathrm{~mm} \times 0.1 \mathrm{~mm}\end{array}$ & $\begin{array}{c}0.5,1.7,3.4,5.6 \text { and } 8.3 \text { for } \\
\text { the rectangular } \\
\text { protuberances numbered } 1 \text {, } \\
2,3,4 \text { and } 5 \text {, respectively }\end{array}$ \\
\hline Case 3 & 5 & $\begin{array}{c}\text { Five rectangular } \\
\text { protuberances; } \\
\text { Five triangular } \\
\text { protuberances; } \\
\text { Five trapezoidal } \\
\text { protuberances }\end{array}$ & $\begin{array}{l}\text { The dimensions of } \\
\text { each protuberance } \\
\text { shape are fixed. } \\
\text { see Figure 1B }\end{array}$ & $\begin{array}{c}\text { See Figure } 1 \mathrm{C}: 0.5,1.7,3.4, \\
5.6 \text { and } 8.3 \text { for the } \\
\text { protuberances numberd } 1 \text {, } \\
2,3,4 \text { and } 5 \text {, respectively }\end{array}$ \\
\hline
\end{tabular}

\subsection{Mathematical Model}

In this calculation, only surface catalytic reactions are considered. As the size of the combustion chamber is small and the mixture gas velocity is slow, the fluid volume force and the dissipative effect can be neglected, and the gas reaction and radiation have not been taken into account either. The fluid flow is described by the Navier-Stokes Equation. The conservation equations of continuity, momentum, energy and species are used in this simulation. All the mathematical models [42] are described as follows:

(1) Continuity equation:

$$
\frac{\partial(\rho u)}{\partial x}+\frac{1}{r} \frac{\partial(r \rho v)}{\partial r}=0
$$

(2) Momentum equation:

$$
\begin{gathered}
\frac{\partial(\rho u u)}{\partial x}+\frac{\partial(\rho u v)}{\partial r}=-\frac{\partial P}{\partial x}+\frac{\partial}{\partial x}\left[\frac{4}{3} \mu \frac{\partial u}{\partial x}-\frac{2}{3} \mu \frac{1}{r} \frac{\partial(r v)}{\partial r}\right]+\frac{1}{r} \frac{\partial}{\partial r}\left[\mu r\left(\frac{\partial v}{\partial x}+\frac{\partial u}{\partial r}\right)\right] \\
\frac{\partial(\rho u v)}{\partial x}+\frac{\partial(\rho v v)}{\partial r}=-\frac{\partial P}{\partial r}+\frac{\partial}{\partial r}\left[\frac{4}{3} \mu \frac{\partial v}{\partial r}-\frac{2}{3} \mu\left(\frac{v}{r}+\frac{\partial u}{\partial r}\right)\right]+\frac{2 u}{r}\left(\frac{\partial v}{\partial x}-\frac{v}{r}\right)+\frac{\partial}{\partial x}\left[\mu\left(\frac{\partial v}{\partial x}+\frac{\partial u}{\partial r}\right)\right]
\end{gathered}
$$

(3) Energy equation:

$$
\frac{\partial(\rho u h)}{\partial x}+\frac{\partial(\rho v h)}{\partial r}=\frac{\partial}{\partial x}\left(\lambda \frac{\partial T}{\partial x}\right)+\frac{1}{r} \frac{\partial}{\partial r}\left(r \lambda \frac{\partial T}{\partial r}\right)+\frac{\partial}{\partial x}\left(\sum_{i=1}^{n} h_{i} \rho D_{i} \frac{\partial Y_{i}}{\partial x}\right)+\frac{\partial}{\partial r}\left(\sum_{i=1}^{n} h_{i} \rho D_{i} \frac{\partial Y_{i}}{\partial r}\right)
$$

(4) Composition equation:

$$
\frac{\partial\left(\rho u Y_{i}\right)}{\partial x}+\frac{\partial\left(\rho v Y_{i}\right)}{\partial r}=\frac{\partial}{\partial x}\left(\rho D_{i} \frac{\partial Y_{i}}{\partial x}\right)+\frac{1}{r} \frac{\partial}{\partial r}\left(r \rho D_{i} \frac{\partial Y_{i}}{\partial r}\right)+R_{i}(i=1,2, \ldots n)
$$

(5) The ideal gas state equation:

$$
P=\rho R T \sum_{i=1}^{n} \frac{Y_{i}}{M_{i}}(i=1,2, \ldots n)
$$

where $\rho$ is the density of the mixture $\left(\mathrm{kg} / \mathrm{m}^{3}\right) ; T$ is temperature $(\mathrm{K}) ; u$ and $v$ are $x$-direction velocity $(\mathrm{m} / \mathrm{s})$ and $r$-direction velocity $(\mathrm{m} / \mathrm{s})$, respectively; $\lambda$ is the thermal conductivity of fluid $(\mathrm{W} / \mathrm{m} \cdot \mathrm{K})$; $Y_{i}$ is the mass fraction of species $i ; h_{i}$ is specific enthalpy of species $i(\mathrm{~J} / \mathrm{kg}) ; R_{i}$ is the generation or 
consumption rate of species $i ; D_{i}$ is mixed average diffusion coefficient of species $i ; M_{i}$ is molecular weight of species $i(\mathrm{~kg} / \mathrm{mole})$.

\subsection{Grid Method and Boundary Conditions}

The CFD software Fluent 6.3 (Fluent Inc., Lebanon, NH, USA) and a 2D model are adopted in this simulation. Different mesh sizes have been tested to ensure the grid-independence. The grid size is taken as $0.01 \mathrm{~mm}$, the wall grids as well as slight protuberance grids are handled with encryption processing. The total mesh grid cells are 34,033 and 35,000-38,000 for the smooth tube and micro-tubes with slight protuberances, respectively. In addition, the physical model is millimeter scale, inlet velocity is set as $1 \mathrm{~m} / \mathrm{s}$, Reynolds number is about 193, thus, laminar flow and species transport models are adopted in our present simulation.

As for the boundary conditions, the velocity inlet and pressure outlet are specified at the entrance and the exit of the combustor, respectively. The inlet temperature is fixed at $573 \mathrm{~K}$, the equivalence ratio of methane-moist air is 0.8 , mass fraction of $\mathrm{CH}_{4}, \mathrm{O}_{2}, \mathrm{H}_{2} \mathrm{O}$ are $0.0405,0.2024,0.0911$, respectively. Moreover, the outer wall surface is insulating, the inner wall surface is covered with platinum catalyst and the site density of $\mathrm{Pt}(\mathrm{s})$ is set to be $2.72 \times 10^{-9} \mathrm{~mol} / \mathrm{cm}^{2}$, fluid-solid coupling is used in the simulation. All of the governing equations are solved with the SIMPLE algorithm and the second order upwind discretization. The simulation is considered to converge when the residuals of all governing equations approached steady state, namely, the absolute criteria of energy equation is smaller than $10^{-6}$ and the absolute criteria of other conservation equations (continuity, momentum and species equations) are all smaller than $10^{-5}$.

\section{Catalytic Combustion Mechanisms}

In terms of micro-scale combustion, the surface area to volume ratio becomes larger, and gas-phase (homogeneous) combustion is difficult to maintain due to both wall thermal losses and chemical radical losses [47]. Moreover, the reaction temperature of methane is low, so gas-phase reactions do not occur under such conditions, and the surface reaction has an inhibitory effect on the space reactions [48], thus, gas phase reactions of $\mathrm{CH}_{4}$ can be ignored in this work [48-51]. The detailed kinetic reaction mechanism (Supplementary Materials Table S1) of methane/moist air on the platinum catalytic surface is applied [52]. The heterogeneous reaction mechanism has 24 elementary steps, which contain nine kinds of gaseous components $\left(\mathrm{CH}_{4}, \mathrm{O}_{2}, \mathrm{H}_{2} \mathrm{O}, \mathrm{CO}, \mathrm{CO}_{2}, \mathrm{H}_{2}, \mathrm{O}, \mathrm{H}, \mathrm{OH}\right)$ and 11 surface species (PT(s), O(s), $\mathrm{CH}_{3}(\mathrm{~s}), \mathrm{CH}_{2}(\mathrm{~s}), \mathrm{CH}(\mathrm{s}), \mathrm{C}(\mathrm{s}), \mathrm{H}(\mathrm{s}), \mathrm{OH}(\mathrm{s}), \mathrm{CO}(\mathrm{s}), \mathrm{CO}_{2}(\mathrm{~s}), \mathrm{H}_{2} \mathrm{O}(\mathrm{s})$ ). The 24-step surface reaction mechanism has been successfully used to investigate the catalytic combustion of methane, and its accuracy has also been demonstrated in previous works $[47,52,53]$. The applied reaction mechanism is used without modification, and as mentioned, gas phase reactions are not taken into account in this study.

\section{Results and Discussion}

In this work, methane/moist air equivalence ratio is 0.8 , inlet velocity is $1.0 \mathrm{~m} / \mathrm{s}$ under $0.1 \mathrm{MPa}$ and $573 \mathrm{~K}$. At first, the combustion characteristics of each circular tube reactor with single different dimension rectangular protuberances (Figure 1A) are investigated separately, then the rectangular protuberances $(0.2 \mathrm{~mm} \times 0.1 \mathrm{~mm})$ with numbers increasing from 0 to 5 , and distances away from the entrance of 5, 17, 34, 56 and $83 \mathrm{~mm}$, respectively, are studied. Finally, the effects of different protuberance shapes (Figure 1B,C) on combustion are compared in the paper.

\subsection{The Sizes of Single Rectangular Protuberance}

Figure 2A indicates that the reaction occurs immediately as the mixture gas enters the micro-tube. Because the mixing and collision among the mixture gas is severe, the Arrhenius reaction rate of $\mathrm{CH}_{4}$ is high and then tends to stabilize at $1 \mathrm{~mm}$ away from the entrance; Moreover, the Arrhenius reaction rate of $\mathrm{CH}_{4}$ is approximately the same except that in the vicinity of the slight protuberance surfaces. 
All of the $\mathrm{CH}_{4}$ reaction rates in non-smooth tubes are higher than that in smooth tubes, as shown in the enlarged drawing of Figure 2A. The slight-protuberances on the inner walls promote the heat transfer and radical diffusion between the flow mixtures and the inner walls. As for the extremely fast reactions in micro-reactors, residence time is an important parameter for heat transfer and radical diffusion. In fact, adding rectangular protuberance on the inner wall reduces the radical distance in the micro-tube, leading to a shorter residence time, $\mathrm{CH}_{4}$ diffuses more quickly from gas phase to the catalyst surface in the smaller channel under this circumstance, thus the reaction rate of $\mathrm{CH}_{4}$ significantly increases in the vicinity of the protuberance surface.

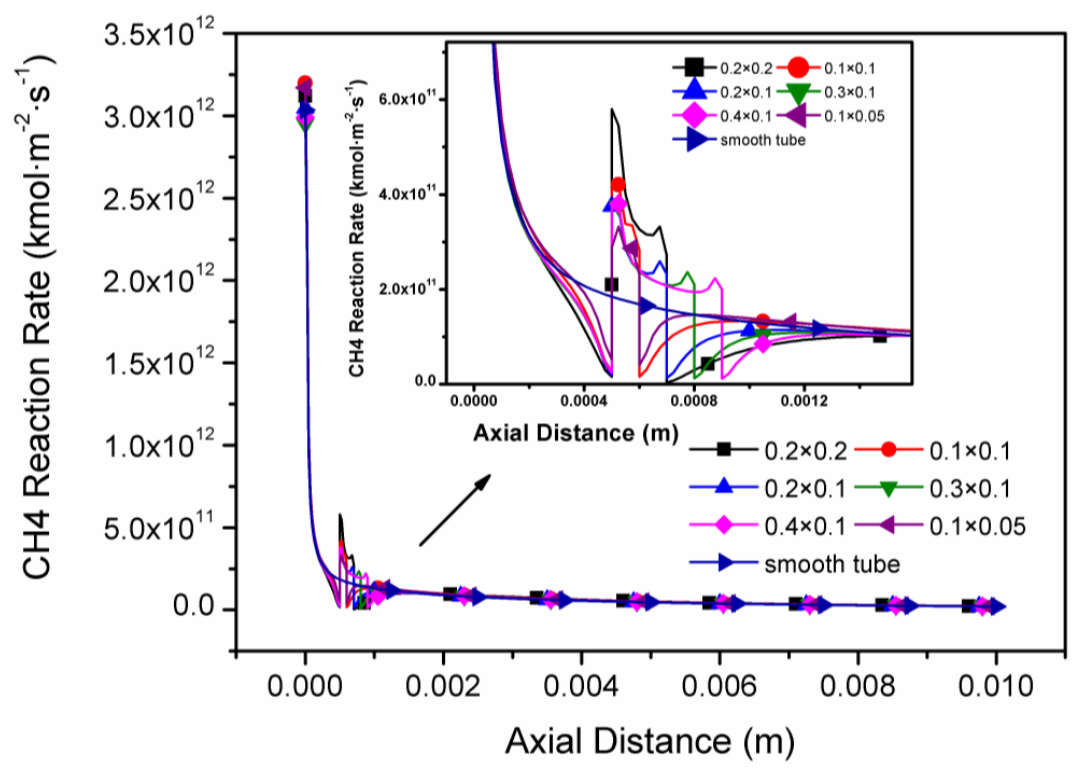

(A) Arrhenius reaction rate of $\mathrm{CH}_{4}$

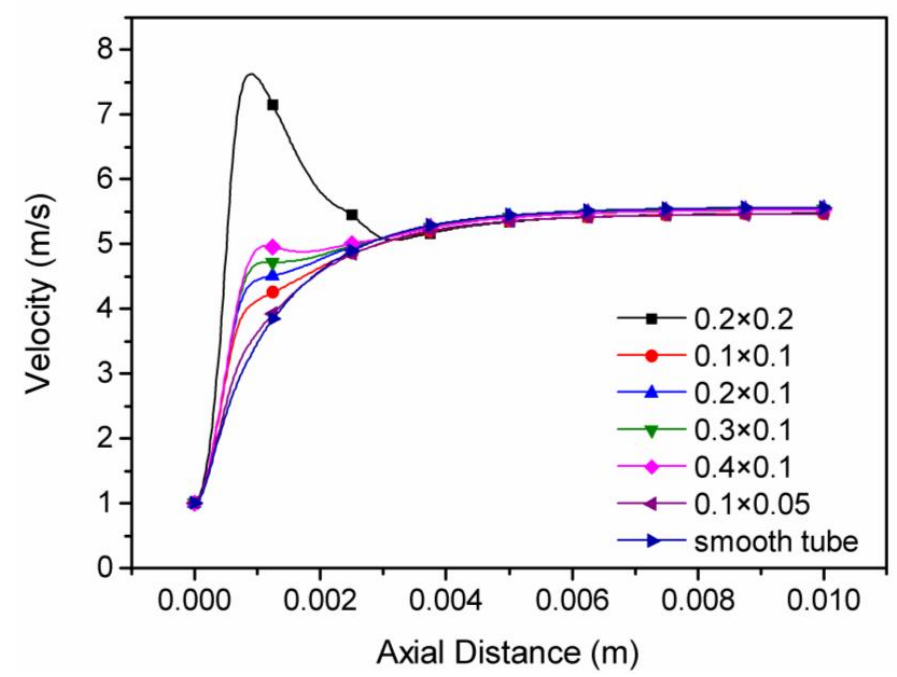

(B) Gas velocity

Figure 2. The influence of rectangular protuberance sizes on: (A) Arrhenius reaction rate of $\mathrm{CH}_{4}$; (B) Gas velocity.

Figure $2 \mathrm{~B}$ shows that in the vicinity of slight protuberances, the centerline velocity along the axis firstly increases and then decreases quickly, and a recirculation zone which can prolong the inflow residence time and enhance the contact between radicals and catalyst will be formed. From Figures 3 and 4 the size of these recirculation zones can be seen clearly, and the area of the low velocity zone increases with the length-height ratio of the protuberances, thus, the fuel has sufficient time to burn. 


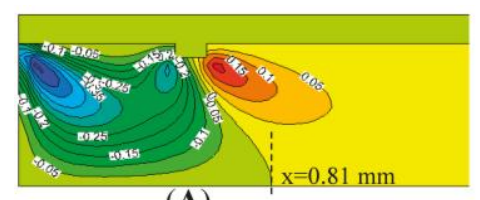

(A)

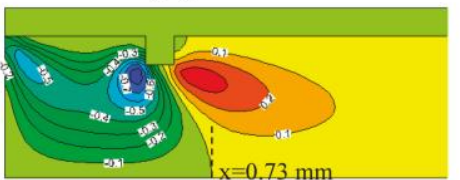

(D)

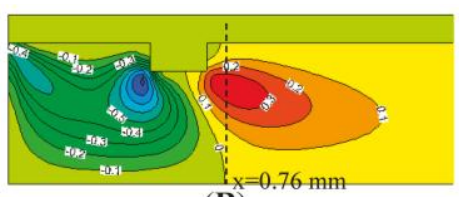

(B)

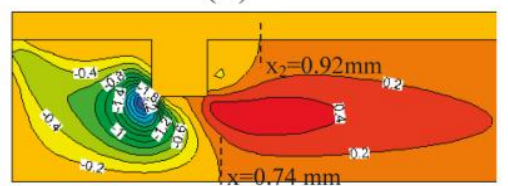

(E)

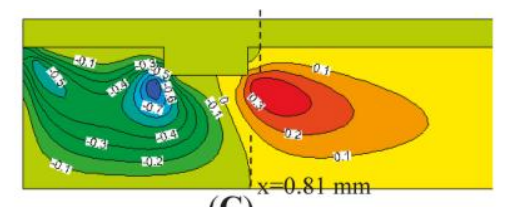

(C)

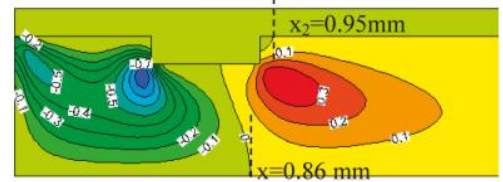

(F)

Figure 3. Contours of r-direction velocity $(\mathrm{m} / \mathrm{s})$ near the protuberance surfaces in the micro-tubes, the dimensions of protuberances are (A) $0.05 \times 0.1 ;$ (B) $0.2 \times 0.1 ;$ (C) $0.3 \times 0.1 ;$ (D) $0.1 \times 0.1 ;(\mathbf{E}) 0.2 \times 0.2$; (F) $0.4 \times 0.1$, units $(\mathrm{mm} \times \mathrm{mm})$.

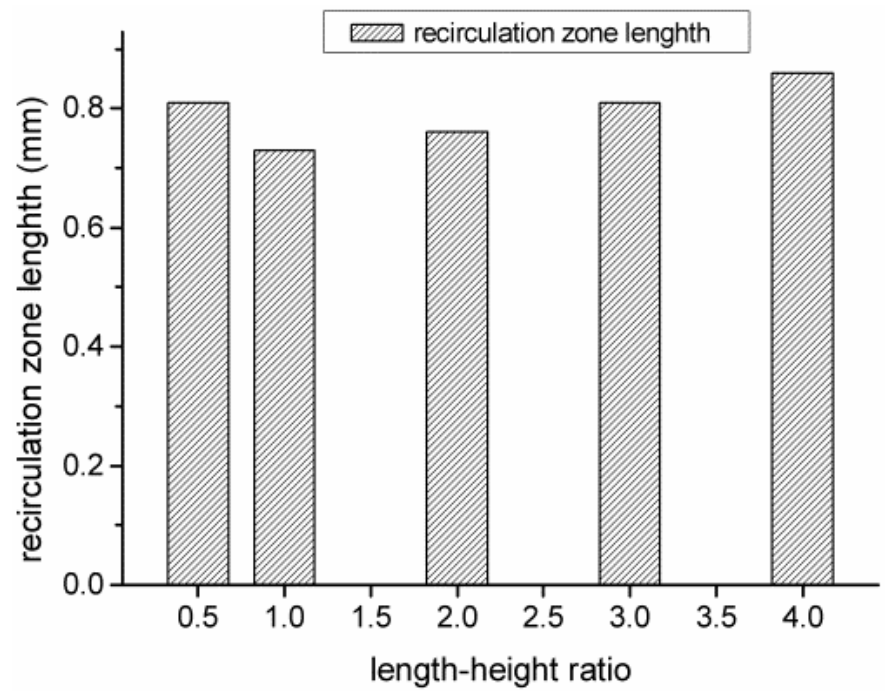

Figure 4. The recirculation zone length for different surface protuberances.

Furthermore, the $r$ (radius)-direction velocity and the recirculation zone increase with the increase of protuberance height and area, which is in accordance with the tendency of the methane reaction rate. Zhai et al. [54] found that most of the energy released from the combustion was used to heat the gas when the reaction took place with a short residence time, therefore, the outlet temperature could rise greatly. As depicted in Figure 5A, the sizes of rectangular protuberances have little influence on the centerline temperature. The maximum outlet temperature difference (in Table 1) is about $25 \mathrm{~K}$ among all simulated reactors, which indicates that a single rectangular protuberance has little effect on the overall residence time. It is inferred that the slight protuberance and cavities can strengthen convective heat transfer so that the temperature distribution is more uniform. Figure 5B shows the mass fraction of methane in different micro-tubes, which indicates that effect of different protuberance sizes on methane conversion rate is slight. Table 2 shows that the methane conversion rates are $87.48 \%-87.88 \%$ for the different tubes.

Figures 2-5 and Table 2 imply that under all simulated conditions, the Arrhenius reaction rate of $\mathrm{CH}_{4}$ increases in the vicinity of a single rectangular protuberance, while the axial temperature and the methane conversion rate are hardly affected by adding a single protuberance to a micro-channel. One explanation is that the reaction near the protuberance is controlled by diffusion, which is in good agreement with our previous research [55]. 


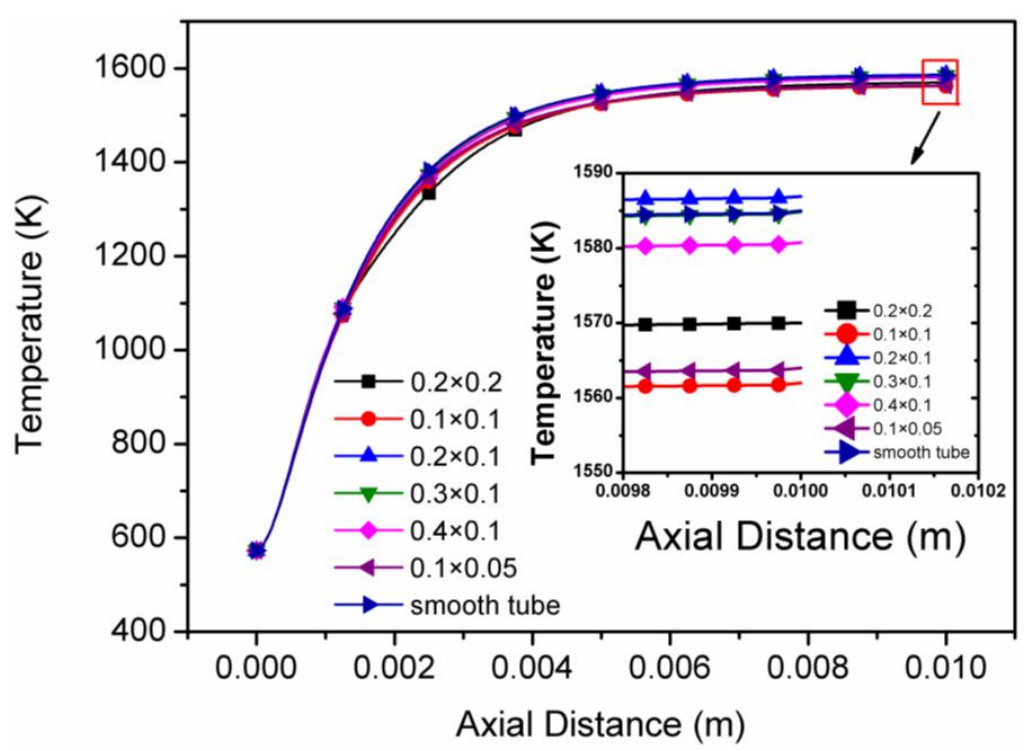

(A) Axial temperature

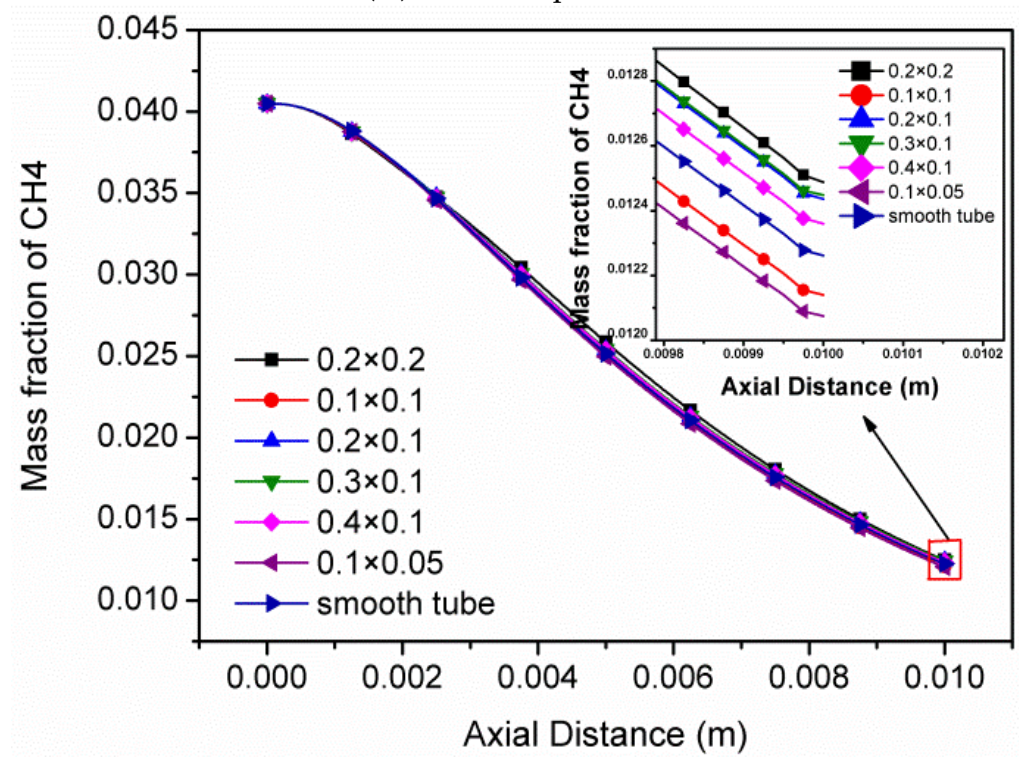

(B) Mass fraction of $\mathrm{CH}_{4}$

Figure 5. The influence of rectangular protuberance sizes on (A) axial temperature and (B) mass fraction of $\mathrm{CH}_{4}$.

Table 2. Outlet temperature, outlet velocity and methane conversion rate in micro-tubes with one rectangular protuberance.

\begin{tabular}{ccccc}
\hline $\begin{array}{c}\text { Protuberance } \\
\text { Type }\end{array}$ & $\begin{array}{c}\text { Protuberance } \\
\text { Sizes }(\mathbf{m m} \times \mathbf{m m})\end{array}$ & $\begin{array}{c}\text { Outlet } \\
\text { Temperature (K) }\end{array}$ & $\begin{array}{c}\text { Outlet Velocity } \\
(\mathbf{m} / \mathbf{s})\end{array}$ & $\begin{array}{c}\text { Methane Conversion } \\
\text { Rate (\%) }\end{array}$ \\
\hline (a) & $0.1 \times 0.05$ & 1565 & 5.46 & 87.88 \\
(b) & $0.1 \times 0.1$ & 1563 & 5.47 & 87.82 \\
(c) & $0.2 \times 0.2$ & 1571 & 5.48 & 87.48 \\
(d) & $0.2 \times 0.1$ & 1588 & 5.56 & 87.57 \\
(e) & $0.3 \times 0.1$ & 1586 & 5.54 & 87.50 \\
(f) & $0.4 \times 0.1$ & 1582 & 5.53 & 87.60 \\
(g) & Smooth tube & 1585 & 5.57 & 87.56 \\
\hline
\end{tabular}




\subsection{The Number of Rectangular Protuberances}

The addition of slight protuberances on the inner wall leads to an increment of the axial surface area, but a decrease of the longitudinal distance in the micro-tube. Figure $6 \mathrm{~A}$ illustrates that the trends of the effect on methane conversion rate caused by 1-5 rectangle protuberances are almost the same. After $1 \mathrm{~mm}$ from the entrance, the influence of the number of protuberances on the Arrhenius reaction rate of $\mathrm{CH}_{4}$ decreases as the mixtures flow towards the exit. Researchers have demonstrated that the residence time can be reduced by augmenting the gas velocity or increasing the operation pressure while keeping the channel size constant [55]. Figure 6B shows the influence of protuberance number on the gas velocity. It indicates that the gas velocity has increased to $4.5-7.0 \mathrm{~m} / \mathrm{s}$ in the vicinity of the protuberances, while the velocity of a smooth tube gradually increases from 1 to $3.5 \mathrm{~m} / \mathrm{s}$, at the inlet and $2 \mathrm{~mm}$ away from the entrance, respectively, then remains stable at $5.5 \mathrm{~m} / \mathrm{s}$ after $4 \mathrm{~mm}$ from the entrance. The maximum outlet velocity difference between a non-smooth tube and a smooth tube is about $1.2 \mathrm{~m} / \mathrm{s}$.

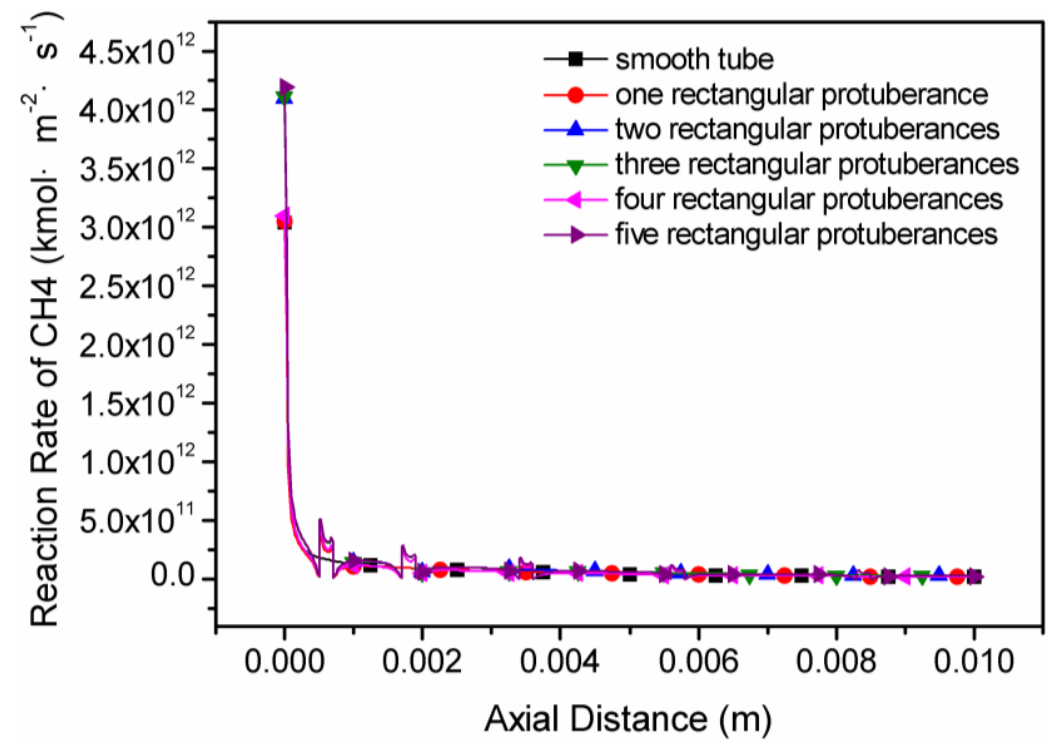

(A) Arrhenius reaction rate of $\mathrm{CH}_{4}$

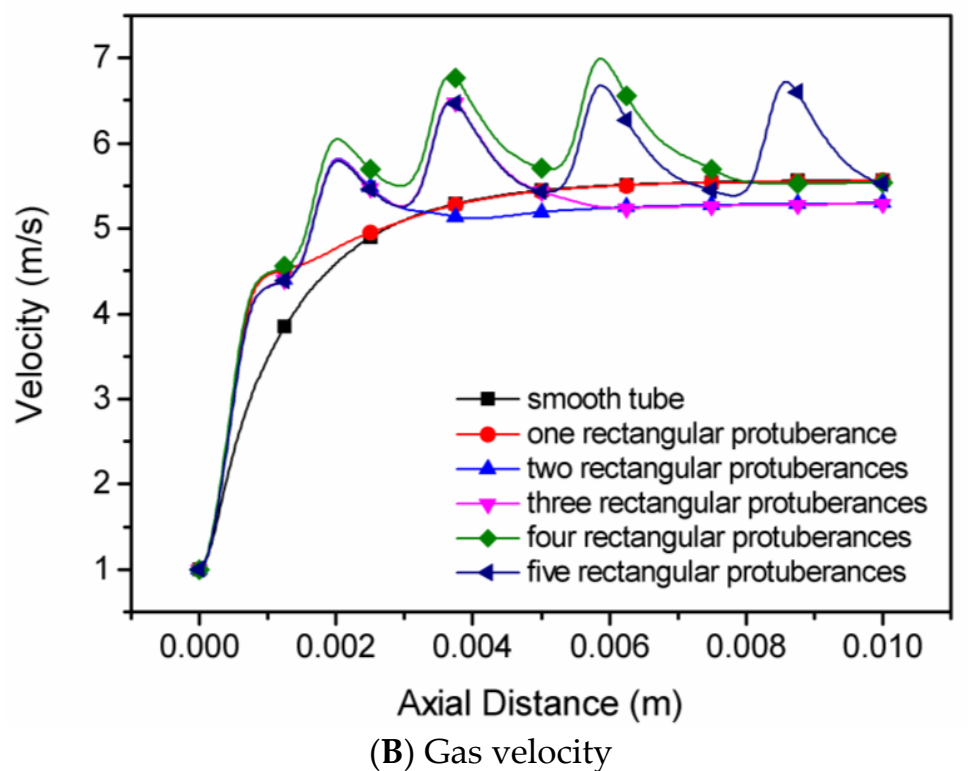

Figure 6. The influence of rectangular protuberance number on (A) Arrhenius reaction rate of $\mathrm{CH}_{4}$ and (B) gas velocity. 
Figure 7 shows the contours of $x$-velocity and r-velocity $(\mathrm{m} / \mathrm{s})$ in the micro-tubes with $0-5$ rectangular protuberances, the results indicate that adding slight protuberances on the wall increases the area of the recirculation zones at low velocity, and the protuberance number has a positive effect on the mixture gas flow in the micro-tube channel. The variations of Arrhenius reaction rate of $\mathrm{CH}_{4}$ and gas velocity are similar to the experimental observations on the hydrogen-air combustion characteristics of a small-scale reactor with different catalyst layouts and configuration [51], because the cavities in a small-scale system can collect radicals and hot gas from upstream, which could serve as a heat source to promote the reaction and provide a low-velocity region to sustain gas-phase reactions.

$\times$ Velocity: $\quad 0.51 .52 .53 .54 .55 .56 .5$
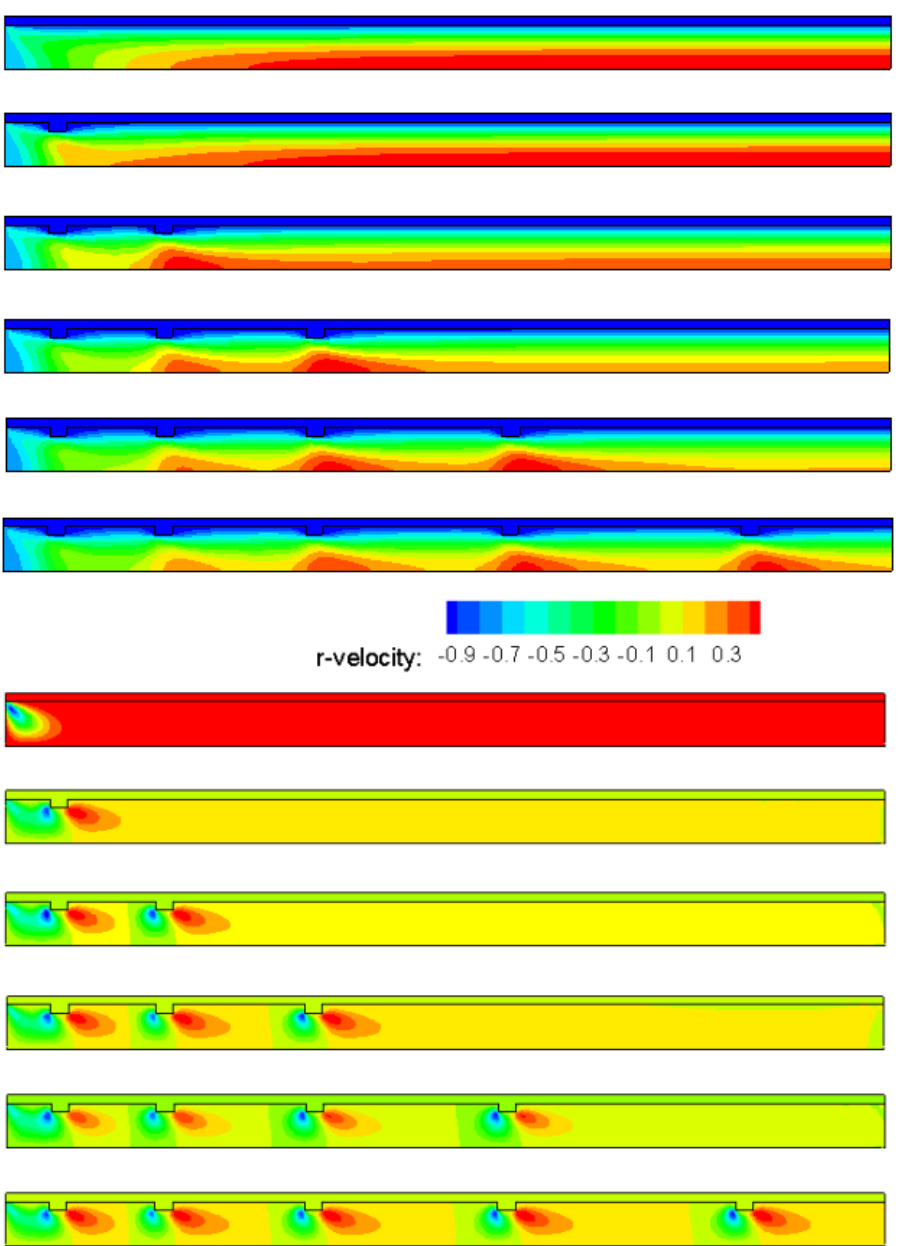

Figure 7. Contours of $x$-velocity and $r$-velocity $(\mathrm{m} / \mathrm{s})$ in the micro-tubes with $0-5$ rectangular protuberances $(0.2 \mathrm{~mm} \times 0.1 \mathrm{~mm})$.

Figure 8A shows that the average temperature of methane/moist air increases sharply and then basically remains unchanged along the axis of the micro-tube reactors, and the temperature stays stable after $4 \mathrm{~mm}$ away from the inlet (temperature contours in the micro-tubes with 0-5 rectangular protuberances can be seen in Supplementary Materials Figure S1). The maximum average outlet temperature difference is about $80 \mathrm{~K}$ between the different simulated micro-tubes. Figure $8 \mathrm{~B}$ indicates that different protuberance numbers result in slightly different influences on the mass fraction of methane. In the micro-tube with one rectangular protuberance, the mass fraction of methane is the highest and the methane conversion rate is the lowest at the outlet. On the contrary, the conversion rate of methane is the highest in the micro-tube with five rectangular protuberances. Note that, the contour 
line variation of temperature and mass fraction of methane is almost smooth, but the lines of reaction rate and gas velocity bulged out on/near the protuberances. Two speculations can be put forth to explain this: (1) after gas velocity increase caused by protuberances, the gas mixture does not have enough time to diffuse from the gas phase to the catalyst surfaces; (2) the reaction on the protuberance surface is controlled by gas-phase mass transfer, therefore, the temperature and the conversion rate of methane shows only a slight change in the micro-tube reactors.

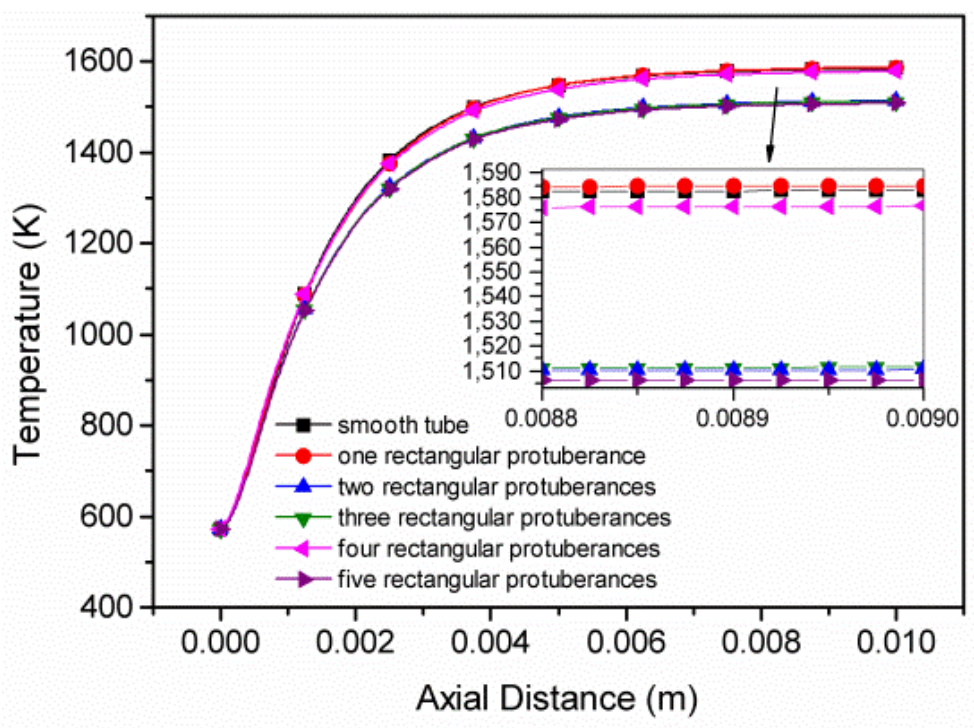

(A) axial temperature

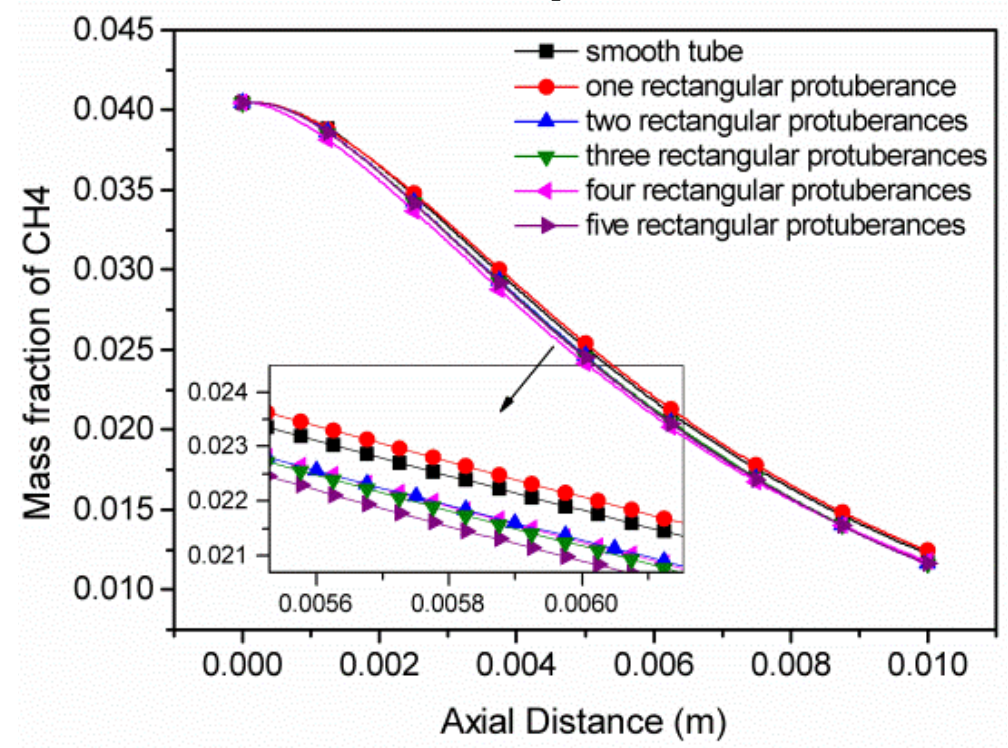

(B) mass fraction of $\mathrm{CH}_{4}$

Figure 8. Influence of rectangular protuberance number on: (A) axial temperature and (B) mass fraction of $\mathrm{CH}_{4}$.

\subsection{The Shape of Protuberances}

In Section 4.2, the conversion rate of methane is the highest in the micro-tube with five rectangular protuberances. To further study the topic, the effect of protuberance shape on methane/moist air catalytic combustion has been studied in the micro-tubes with five rectangular, five trapezoidal and five triangular protuberances, respectively. Compared to the smooth tube, the Arrhenius reaction rate of $\mathrm{CH}_{4}$ near the protuberances on non-smooth tube inner walls increases to a varying extent, while the 
degree of increase reduces gradually as the chemical reactions continue on the protuberance surfaces as shown in Figure 10A. The smaller the distance from the exit, the less the protuberance impact on the methane reaction rate. Moreover, the Arrhenius reaction rate of $\mathrm{CH}_{4}$ is the largest in the vicinity of rectangular protuberances, and is the smallest in the vicinity of trapezoidal protuberances, as shown in the enlarged drawing of Figure 10A. Figure 10B depicts the influence of the protuberance shape on the axial velocity variation of gas mixtures in micro-tubes. In the micro-tube with five rectangular protuberances, the average flow velocity is the highest in the $x$-axis direction, indicating that the area of the recirculation zone is also the largest one. It can be obviously figured out that the average velocity of the smooth tube is the lowest (contours of the x-velocity and r-velocity in the micro-tubes with different protuberance shapes can be seen in Supplementary Materials Figure S2).

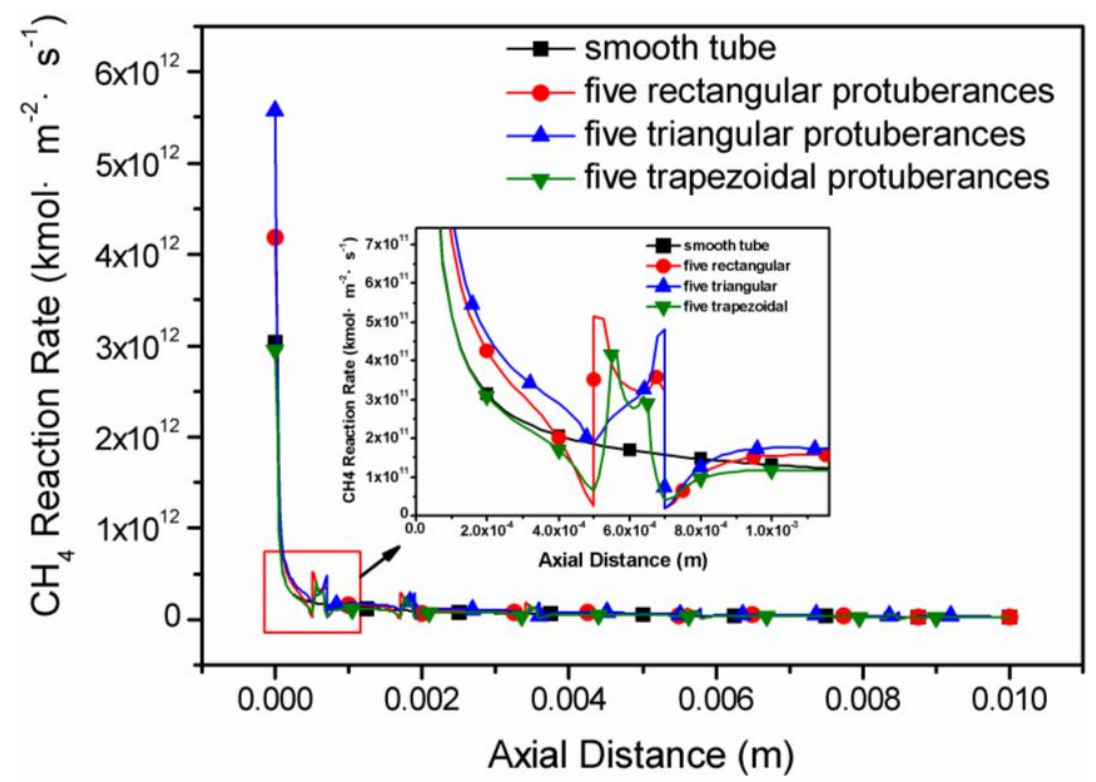

(A) Arrhenius reaction rate of $\mathrm{CH}_{4}$

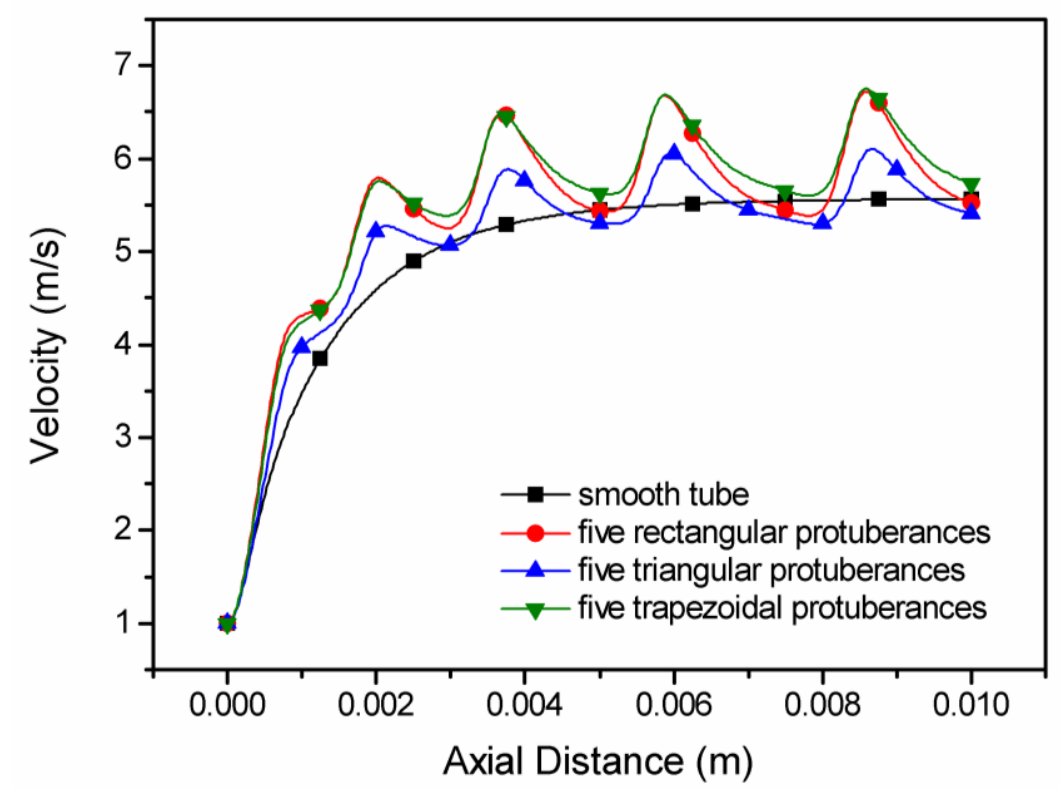

(B) Gas velocity

Figure 9. Cont. 


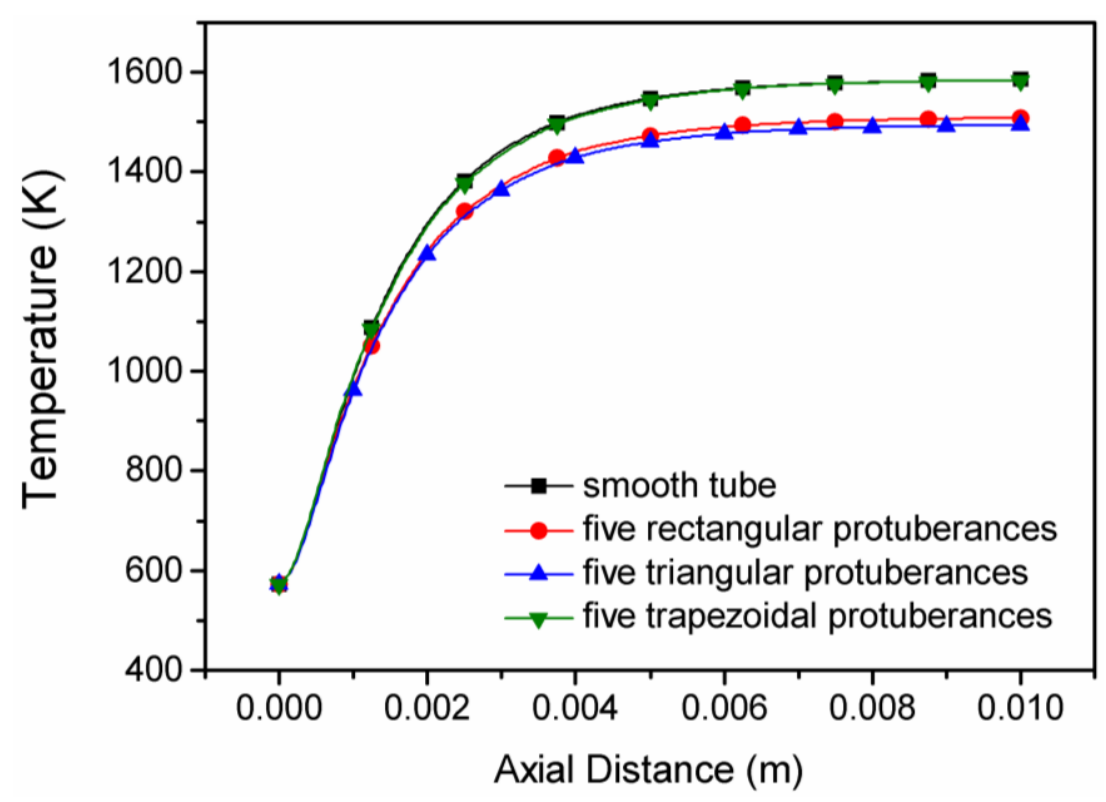

(C) Axial temperature

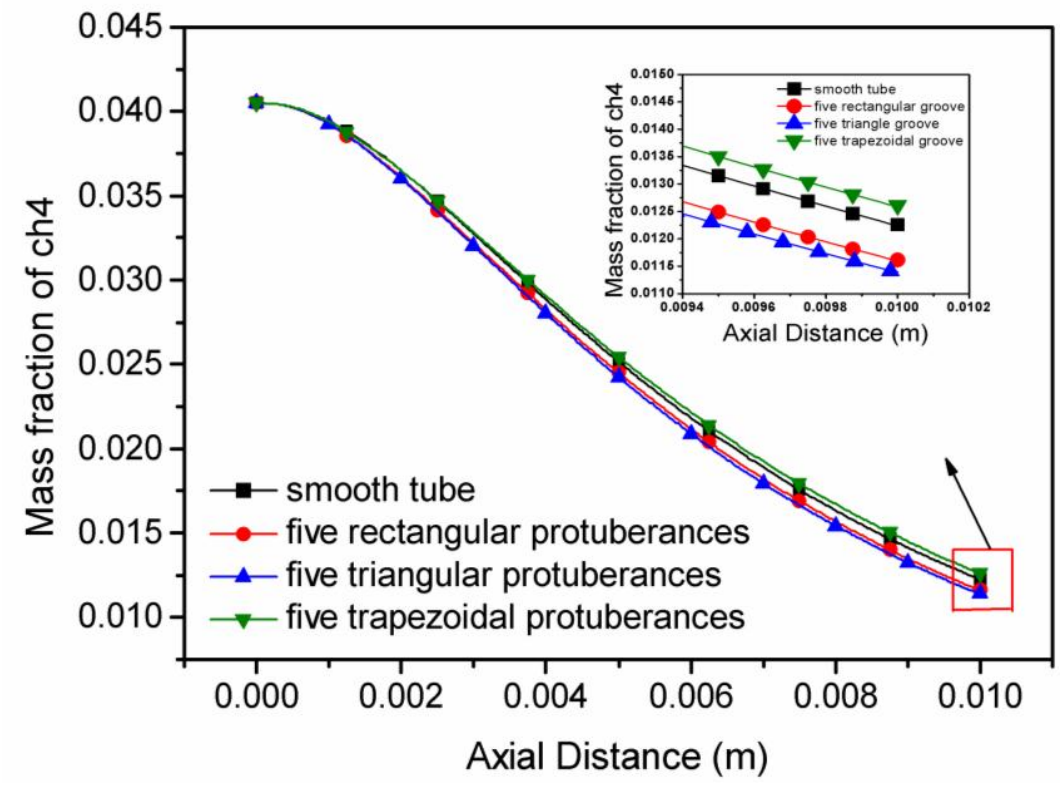

(D) Mass fraction of $\mathrm{CH}_{4}$

Figure 10. The influence of the protuberance shape on (A) Arrhenius reaction rate of $\mathrm{CH}_{4} ;(\mathbf{B})$ Gas velocity; (C) Axial temperature; (D) Mass fraction of $\mathrm{CH}_{4}$.

As shown in Figure 10C, the maximum difference of the outlet temperature is about $200 \mathrm{~K}$ in the micro-tubes (contours of temperature in the micro-tubes with different protuberance shape can be seen in Supplementary Materials Figure S3). As for the different protuberance shapes, the outlet temperatures are 1600, 1480 and $1400 \mathrm{~K}$ for the five trapezoidal, rectangular and triangular protuberances, respectively.

When the reaction occurs with a short residence time, most of the heat released from the combustion is used to heat the mixture gas, which leads to the rise of the outlet temperature. However, the participation of water steam in the inlet gas and the production of water could impact the outlet temperature, as with the increasing gas temperature, the specific heat of $\mathrm{H}_{2} \mathrm{O}$ is reduced under constant pressure, thus, outlet temperature may also be reduced [55]. With the increase of temperature along the axial direction the mass fraction of $\mathrm{CH}_{4}$ decreases gradually, as displayed in Figure 10D. 
It is noted that the mass fraction of $\mathrm{CH}_{4}$ at the outlet, is the maximum for the five trapezoidal protuberances and the minimum for the five triangular protuberances, which is in accordance with the value of the outlet temperature. As for the variation of methane conversion, the conversion rate is the highest in the micro-tube with five triangular protuberances, while the lowest one is in the micro-tube with five trapezoidal protuberances. Therefore, in all simulated methane/moist air catalytic combustion conditions, the micro-tube with five triangular protuberances has the peak efficiency and is recommended for high efficiency reactors.

\section{Conclusions}

A micro-tube reactor with multiple slight protuberances is investigated in this paper. Through the analysis of methane/moist air catalytic combustion in the micro-tube reactors with different slight protuberances, the following main conclusions are derived:

(1) The Arrhenius reaction rate of $\mathrm{CH}_{4}$ and flow velocity increase with the increase of protuberance height and area, while the axial temperature and the methane conversion rate are affected little in each micro-tube with one single rectangular protuberance.

(2) Cavities and recirculation zones are formed due to the addition of slight protuberances on the inner wall. For a number of rectangular protuberances from $0-5$, the influence of protuberance number on the reaction rate decreases as the mixture gas flows towards the exit. The conversion rate of methane is the highest in the micro-tube with five rectangular protuberances.

(3) The shape of slight protuberances has a greater influence than protuberance number. The methane conversion rate in the micro-tubes decreases progressively in the order five triangular slight protuberances $>$ five rectangular protuberances $>$ five trapezoidal protuberances $>$ smooth tube.

(4) In all simulated methane/moist air catalytic combustion conditions, the micro-tube with five triangular protuberances has the peak efficiency and is recommended for high efficiency reactors.

Supplementary Materials: The following are available online at www.mdpi.com/1996-1073/9/6/421/s1. Table S1: Mechanism of methane reactions on Pt surface, Figure S1: The contours of temperature (K) in the micro-tubes with 0-5 rectangular protuberances $(0.2 \mathrm{~mm} \times 0.1 \mathrm{~mm})$, Figure S2: The $x$-velocity and $r$-velocity $(\mathrm{m} / \mathrm{s})$ contours in the micro-tubes with different protuberance shapes, Figure S3: The contours of temperature (K) in the micro tubes with different protuberance shapes.

Acknowledgments: This work is financially supported by the National Natural Science Foundation of China (Project Nos.: 51276207 \& 50876118).

Author Contributions: Ruirui Wang, Jingyu Ran, Xuesen Du, Juntian Niu and Wenjie Qi checked and discussed the simulation results. Ruirui Wang confirmed the series of simulation parameters and arranged and organized the entire simulation process. Jingyu Ran participated in establishing the simulation model. Xuesen Du, Juntian Niu and Wenjie Qi revised the paper. Jingyu Ran and Xuesen Du made many useful comments and simulation suggestions. In addition, all authors reviewed the manuscript.

Conflicts of Interest: The authors declare no conflict of interest.

\section{References}

1. Chia, L.C.; Feng, B. The development of a micropower (micro-thermophotovoltaic) device. J. Power Sources 2007, 165, 455-480. [CrossRef]

2. Yang, W.M.; Chua, K.J.; Pan, J.F.; Jiang, D.Y.; An, H. Development of micro-thermophotovoltaic power generator with heat recuperation. Energy Convers. Manag. 2014, 78, 81-87. [CrossRef]

3. Beckers, J.; Gaudillère, C.; Farrusseng, D.; Rothenberg, G. Marrying gas power and hydrogen energy: A catalytic system for combining methane conversion and hydrogen generation. Green Chem. 2009, 11, 921-925. [CrossRef]

4. Svetovoy, V.; Postnikov, A.; Uvarov, I.; Sanders, R.; Krijnen, G. Overcoming the fundamental limit: Combustion of a hydrogen-oxygen mixture in micro- and nano-bubbles. Energies 2016, 9, 94. [CrossRef]

5. Zhang, Y.; Zuo, Z.; Liu, J. Numerical analysis on combustion characteristic of leaf spring rotary engine. Energies 2015, 8, 8086-8109. [CrossRef] 
6. Minotti, A.; Teofilatto, P. Swirling combustor energy converter: $\mathrm{H}_{2}$ / Air simulations of separated chambers. Energies 2015, 8, 9930-9945. [CrossRef]

7. Baigmohammadi, M.; Tabejamaat, S.; Zarvandi, J. Numerical study of the behavior of methane-hydrogen/air pre-mixed flame in a micro reactor equipped with catalytic segmented bluff body. Energy 2015, 85, 117-144. [CrossRef]

8. Wiswall, J.T.; Li, J.; Wooldridge, M.S.; Im, H.G. Effects of platinum stagnation surface on the lean extinction limits of premixed methane/air flames at moderate surface temperatures. Combust. Flame 2011, 158, 139-145. [CrossRef]

9. Li, Y.-H.; Hsu, H.-W.; Lien, Y.-S.; Chao, Y.-C. Design of a novel hydrogen-syngas catalytic mesh combustor. Int. J. Hydrogen Energy 2009, 34, 8322-8328. [CrossRef]

10. Kaisare, N.S.; Deshmukh, S.R.; Vlachos, D.G. Stability and performance of catalytic microreactors: Simulations of propane catalytic combustion on Pt. Chem. Eng. Sci. 2008, 63, 1098-1116. [CrossRef]

11. Persson, K.; Pfefferle, L.D.; Schwartz, W.; Ersson, A.; Järås, S.G. Stability of palladium-based catalysts during catalytic combustion of methane: The influence of water. Appl. Catal. B Environ. 2007, 74, 242-250. [CrossRef]

12. Mantzaras, J. Understanding and modeling of thermofluidic processes in catalytic combustion. Catal. Today 2006, 117, 394-406. [CrossRef]

13. Salciccioli, M.; Stamatakis, M.; Caratzoulas, S.; Vlachos, D.G. A review of multiscale modeling of metal-catalyzed reactions: Mechanism development for complexity and emergent behavior. Chem. Eng. Sci. 2011, 66, 4319-4355. [CrossRef]

14. Chen, X.; Zhang, Y.; Zhang, Y. Effect of $\mathrm{CH}_{4}$-air ratios on gas explosion flame microstructure and propagation behaviors. Energies 2012, 5, 4132-4146. [CrossRef]

15. Lang, J.; Cheng, S.; Zhou, Y.; Zhao, B.; Wang, H.; Zhang, S. Energy and environmental implications of hybrid and electric vehicles in China. Energies 2013, 6, 2663-2685. [CrossRef]

16. Korup, O.; Goldsmith, C.F.; Weinberg, G.; Geske, M.; Kandemir, T.; Schlögl, R.; Horn, R. Catalytic partial oxidation of methane on platinum investigated by spatial reactor profiles, spatially resolved spectroscopy, and microkinetic modeling. J. Catal. 2013, 297, 1-16. [CrossRef]

17. Chin, Y.-H.; Buda, C.; Neurock, M.; Iglesia, E. Selectivity of chemisorbed oxygen in C-H bond activation and $\mathrm{CO}$ oxidation and kinetic consequences for $\mathrm{CH}_{4}-\mathrm{O}_{2}$ catalysis on Pt and Rh clusters. J. Catal. 2011, 283, $10-24$. [CrossRef]

18. Li, J.; Zhong, B. Experimental investigation on heat loss and combustion in methane/oxygen micro-tube combustor. Appl. Therm. Eng. 2008, 28, 707-716. [CrossRef]

19. Burch, R.; Urbano, F.J. Investigation of the active state of supported palladium catalysts in the combustion of methane. Appl. Catal. A Gen. 1995, 124, 121-138. [CrossRef]

20. Schicks, J.M.; Spangenberg, E.; Giese, R.; Steinhauer, B.; Klump, J.; Luzi, M. New approaches for the production of hydrocarbons from hydrate bearing sediments. Energies 2011, 4, 151-172. [CrossRef]

21. Moccia, V.; D'Alessio, J. Burning behaviour of high-pressure $\mathrm{CH}_{4}-\mathrm{H}_{2}$-air mixtures. Energies 2013, 6, 97-116. [CrossRef]

22. Boushaki, T.; Dhué, Y.; Selle, L.; Ferret, B.; Poinsot, T. Effects of hydrogen and steam addition on laminar burning velocity of methane-air premixed flame: Experimental and numerical analysis. Int. J. Hydrogen Energy 2012, 37, 9412-9422. [CrossRef]

23. Persson, K.; Ersson, A.; Jansson, K.; Fierro, J.L.G.; Järås, S.G. Influence of molar ratio on Pd-Pt catalysts for methane combustion. J. Catal. 2006, 243, 14-24. [CrossRef]

24. ViÇes, F.; Lykhach, Y.; Staudt, T.; Lorenz, M.P.A.; Papp, C.; Steinrueck, H.-P.; Libuda, J.; Neyman, K.M.; Gçrling, A. Methane activation by platinum: Critical role of edge and corner sites of metal nanoparticles. Chem. A Eur. J. 2010, 16, 6530-6539.

25. Trevo, D.J.; Cox, D.M.; Kaldor, A. Methane activation on unsupported platinum clusters. J. Am. Chem. Soc. 1990, 112, 3742-3749. [CrossRef]

26. Luntz, A.C.; Bethune, D.S. Activation of methane dissociation on a Pt(111) surface. J. Chem. Phys. 1989, 90, 1274-1280. [CrossRef]

27. Gremminger, A.T.; Pereira de Carvalho, H.W.; Popescu, R.; Grunwaldt, J.-D.; Deutschmann, O. Influence of gas composition on activity and durability of bimetallic $\mathrm{Pd}-\mathrm{Pt} / \mathrm{Al}_{2} \mathrm{O}_{3}$ catalysts for total oxidation of methane. Catal. Today 2015, 258, 470-480. [CrossRef] 
28. Richecoeur, F.; Kyritsis, D.C. Experimental study of flame stabilization in low Reynolds and Dean number flows in curved mesoscale ducts. Proc. Combust. Inst. 2005, 30, 2419-2427. [CrossRef]

29. Pizza, G.; Mantzaras, J.; Frouzakis, C.E.; Tomboulides, A.G.; Boulouchos, K. Suppression of combustion instabilities of premixed hydrogen/air flames in microchannels using heterogeneous reactions. Proc. Combust. Inst. 2009, 32, 3051-3058. [CrossRef]

30. Brambilla, A.; Schultze, M.; Frouzakis, C.E.; Mantzaras, J.; Bombach, R.; Boulouchos, K. An experimental and numerical investigation of premixed syngas combustion dynamics in mesoscale channels with controlled wall temperature profiles. Proc. Combust. Inst. 2015, 35, 3429-3437. [CrossRef]

31. Avc1, A.K.; Trimm, D.L.; Karakaya, M. Microreactor catalytic combustion for chemicals processing. Catal. Today 2010, 155, 66-74. [CrossRef]

32. Tonkovich, A.Y.; Perry, S.; Wang, Y.; Qiu, D.; LaPlante, T.; Rogers, W.A. Microchannel process technology for compact methane steam reforming. Chem. Eng. Sci. 2004, 59, 4819-4824. [CrossRef]

33. Yang, W.M.; Chou, S.K.; Shu, C.; Li, Z.W.; Xue, H. Experimental study of micro-thermophotovoltaic systems with different combustor configurations. Energy Convers. Manag. 2007, 48, 1238-1244. [CrossRef]

34. Baigmohammadi, M.; Tabejamaat, S.; Farsiani, Y. An experimental study of methane-oxygen-carbon dioxide premixed flame dynamics in non-adiabatic cylinderical meso-scale reactors with the backward facing step. Chem. Eng. Proc. Process Intensif. 2015, 95, 105-123. [CrossRef]

35. Li, J.; Chou, S.K.; Yang, W.M.; Li, Z.W. A numerical study on premixed micro-combustion of $\mathrm{CH}_{4}$-air mixture: Effects of combustor size, geometry and boundary conditions on flame temperature. Chem. Eng. J. 2009, 150, 213-222. [CrossRef]

36. Yang, W.; Deng, C.; Zhou, J.; Liu, J.; Wang, Y.; Cen, K. Experimental and numerical investigations of hydrogen-air premixed combustion in a converging-diverging micro tube. Int. J. Hydrogen Energy 2014, 39, 3469-3476. [CrossRef]

37. Ran, J.; Li, L.; Du, X.; Wang, R.; Pan, W.; Tang, W. Numerical investigations on characteristics of methane catalytic combustion in micro-channels with a concave or convex wall cavity. Energy Convers. Manag. 2015, 97, 188-195. [CrossRef]

38. Sun, L.; Jiang, B.; Gu, F. Effects of changes in pipe cross-section on the explosion-proof distance and the propagation characteristics of gas explosions. J. Nat. Gas Sci. Eng. 2015, 25, 236-241. [CrossRef]

39. Li, Y.-H.; Chen, G.-B.; Wu, F.-H.; Cheng, T.-S.; Chao, Y.-C. Effects of catalyst segmentation with cavities on combustion enhancement of blended fuels in a micro channel. Combust. Flame 2012, 159, 1644-1651. [CrossRef]

40. Wan, J.-L.; Fan, A.-W.; Yao, H.; Liu, W.; Gou, X.-L.; Zhao, D.-Q. The impact of channel gap distance on flame splitting limit of $\mathrm{H}_{2}$ /air mixture in microchannels with wall cavities. Int. J. Hydrogen Energy 2014, 39, 11308-11315. [CrossRef]

41. Zhang, L.; Zhu, J.; Yan, Y.; Pan, W.; Yang, Z.; Chen, Y.; Ji, X. Numerical investigation on the transient characteristics of hydrogen production from catalytic autothermal reforming of methane in a micro combustor with multiple cylinders. J. Nat. Gas Sci. Eng. 2014, 19, 251-257. [CrossRef]

42. Niu, J.; Ran, J.; Li, L.; Du, X.; Wang, R.; Ran, M. Effects of trapezoidal bluff bodies on blow out limit of methane/air combustion in a micro-channel. Appl. Therm. Eng. 2016, 95, 454-461. [CrossRef]

43. Veeraragavan, A.; Cadou, C.P. Flame speed predictions in planar micro/mesoscale combustors with conjugate heat transfer. Combust. Flame 2011, 158, 2178-2187. [CrossRef]

44. Veeraragavan, A. On flame propagation in narrow channels with enhanced wall thermal conduction. Energy 2015, 93, 631-640. [CrossRef]

45. Kang, X.; Veeraragavan, A. Experimental investigation of flame stability limits of a mesoscale combustor with thermally orthotropic walls. Appl. Therm. Eng. 2015, 85, 234-242. [CrossRef]

46. Veeraragavan, A.; Beri, J.; Gollan, R.J. Use of the method of manufactured solutions for the verification of conjugate heat transfer solvers. J. Comput. Phys 2016, 307, 308-320. [CrossRef]

47. Saiki, Y.; Suzuki, Y. Effect of wall surface reaction on a methane-air premixed flame in narrow channels with different wall materials. Proc. Combust. Inst. 2013, 34, 3395-3402. [CrossRef]

48. Ran, J.-Y.; Wu, S.; Yang, L.; Zhang, L. The wall heat transfer phenomenon of premixed $\mathrm{CH}_{4} /$ air catalytic combustion in a Pt coated microtube. J. Heat Transfer 2014, 136, 021201. [CrossRef] 
49. Gosiewski, K.; Pawlaczyk, A.; Warmuzinski, K.; Jaschik, M. A study on thermal combustion of lean methane-air mixtures: Simplified reaction mechanism and kinetic equations. Chem. Eng. J. 2009, 154, 9-16. [CrossRef]

50. Federic, J.A.; Wetzel, E.D.; Geil, B.R.; Vlachos, D.G. Single channel and heat recirculation catalytic microburners: An experimental and computational fluid dynamics study. Proc. Combust. Inst. 2009, 32, 3011-3018. [CrossRef]

51. Li, Y.-H.; Chen, G.-B.; Wu, F.-H.; Cheng, T.-S.; Chao, Y.-C. Combustion characteristics in a small-scale reactor with catalyst segmentation and cavities. Proc. Combust. Inst. 2013, 34, 2253-2259. [CrossRef]

52. Deutschmann, O.; Maier, L.I.; Riedel, U.; Stroemman, A.H.; Dibble, R.W. Hydrogen assisted catalytic combustion of methane on platinum. Catal. Today 2000, 59, 141-150. [CrossRef]

53. Schwiedernoch, R.; Tischer, S.; Deutschmann, O.; Warnatz, J. Experimental and numerical investigation of the ignition of methane combustion in a platinum-coated honeycomb monolith. Proc. Combust. Inst. 2002, 29, 1005-1011. [CrossRef]

54. Zhai, X.; Ding, S.; Cheng, Y.; Jin, Y.; Cheng, Y. CFD simulation with detailed chemistry of steam reforming of methane for hydrogen production in an integrated micro-reactor. Int. J. Hydrogen Energy 2010, 35, 5383-5392. [CrossRef]

55. Ran, J.; Qi, W.; Wang, R. Numerical study of the micro-channel rough surface on methane catalytic combustion. J. Eng. Thermophys. 2014, 35, 1244-1247.

(C) 2016 by the authors; licensee MDPI, Basel, Switzerland. This article is an open access article distributed under the terms and conditions of the Creative Commons Attribution (CC-BY) license (http:/ / creativecommons.org/licenses/by/4.0/). 